\title{
Thermal Injury, Intravascular Hemolysis, and Toxic Oxygen Products
}

\author{
John R. Hatherill, Gerd O. Till, Leon H. Bruner, and Peter A. Ward \\ Department of Pathology, The University of Michigan Medical School, Ann Arbor, Michigan 48109-0603
}

\begin{abstract}
Acute thermal injury of rat skin produces an early, acute hemoglobinemia that is associated with the presence in blood of osmotically fragile red cells (RBC) that do not contain on their surfaces measurable amounts of complement components. The hemoglobinemia and the appearance in blood of osmotically fragile $R B C$ appear to be the result of complement activation, which leads to oxygen radical production by neutrophils and damage of RBC. This has been demonstrated in vitro as well as in vivo by the ability of antioxidant interventions or neutrophil or complement depletion procedures to prevent the appearance of osmotically fragile RBC and the release of hemoglobin. These data may be relevant to the complications of hemoglobinemia and hemoglobinuria accompanying thermal injury in humans.
\end{abstract}

\section{Introduction}

Red cell lysis produced in vitro by fluid phase activation of the complement system is a well-known phenomenon that has been explained by a relatively inefficient process associated with a detergent-like effect of the complement-derived membrane attack complex (C5b-9) $(1,2)$. It is also known that endothelial cells and red blood cells $(\mathrm{RBC})^{1}$ can be damaged or destroyed in vitro by oxygen radicals produced by complement or phorbolactivated neutrophils (3-5). Following acute thermal injury in humans there is evidence of both systemic activation of the complement system as well as intravascular hemolysis, the latter being indicated by appearance of hemoglobin in the plasma. The mechanism of hemolysis has not been determined. Infusion into burn patients of red cells derived from normal donors has resulted in accelerated breakdown of the transfused cells, suggesting an active process of red cell destruction $(6,7)$.

We have previously shown that, following acute thermal injury to the skin of rats, systemic activation of the complement system occurs, resulting in appearance in plasma of the complement-derived anaphylatoxin, C5a, formation of leukoaggregates, and sequestration of neutrophils in lung capillaries (8). These events result in iron-dependent injury of pulmonary vas-

\footnotetext{
Address reprint requests to Dr. Ward.

Received for publication 11 September 1985 and in revised form 12 May 1986.
}

1. Abbreviations used in this paper: $\mathrm{CH} 50$, activity units of serum complement causing 50\% lysis of sensitized red cells; CVF, cobra venom factor; DMSO, dimethyl sulfoxide; DMTU, dimethyl thiourea; PEG, polyethylene glycol; PMA, phorbol myristate acetate; RBC, red blood cells; SE, sheep erythrocytes; SEA, antibody-sensitized sheep erythrocytes; SOD, superoxide dismutase; TBS, triethanolamine-buffered saline.

J. Clin. Invest.

(c) The American Society for Clinical Investigation, Inc.

0021-9738/86/09/0629/08 $\$ 1.00$

Volume 78, September 1986, 629-636 cular endothelial cells, the damage perhaps being attributable to generation of hydroxyl radical $\left(\mathrm{HO}^{\circ}\right)$ from blood neutrophils (9). Both the local skin injury as well as the pulmonary microvascular injury are associated with the appearance in plasma of products of lipid peroxidation (9). We now report evidence of intravascular hemolysis in the model of acute thermal injury and the role of complement and toxic oxygen products from activated neutrophils in the destruction of red cells. Our observations suggest that intravascular hemolysis occurring in the thermally injured rats is mainly mediated by oxygen radicals released from complement-activated blood neutrophils, suggesting that complement activation products are only indirectly related to the hemolytic event. These studies appear to be among the first demonstrating that oxygen radicals produced in vivo from neutrophils can cause RBC damage and destruction in vivo.

\section{Methods}

Animals and compounds. Young adult male Long-Evans rats (Charles River Laboratories, Portage, MI) were used throughout these studies. Polyethylene glycol-modified catalase (PEG-catalase, 1,200 U/kg) and polyethylene glycol-modified superoxide dismutase (PEG-SOD, 1,025 $\mathrm{U} / \mathrm{kg}$ ) (Enzon, Inc., South Plainfield, NJ) were injected intravenously 10 min prior to thermal injury. Hydroxyl radical scavengers, dimethyl sulfoxide (DMSO) (Fisher Scientific Company, Fair Lawn, NJ) or dimethyl thiourea (DMTU) (Alfa Products, Danvers, MA), were administered $(1.5 \mathrm{ml} / \mathrm{kg}$ and $1,000 \mathrm{mg} / \mathrm{kg}$, respectively) intraperitoneally 10 min prior to experimental procedures. Animals were anesthetized with ketamine hydrochloride $(90 \mathrm{mg} / \mathrm{kg}$ ) (Parke Davis and Co., Morris Plains, $\mathrm{NJ})$ and xylazine (13 mg/kg) (Haver-Lockhart, Bayvet Division Miles Laboratories, Inc., Shawnee, KS).

Neutrophil and complement depletion. Circulating rat blood neutrophils (PMN) were depleted by intraperitoneal injection of $0.5 \mathrm{ml} / 100 \mathrm{~g}$ body weight of rabbit antineutrophil serum given $18 \mathrm{~h}$ prior to thermal injury, as described $(10,11)$. This manipulation does not affect serum complement levels (10). Cobra venom factor (CVF) was isolated from lyophilized cobra venom (Naja naja) by ion exchange and gel filtration chromatography (12). Complement was depleted by intraperitoneal injection of cobra venom factor ( $40 \mathrm{U} / \mathrm{rat}) 24 \mathrm{~h}$ prior to thermal injury, resulting in complete loss of serum complement activity $(\mathrm{CH} 50)$.

Thermal injury. Anesthetized (ketamine hydrochloride $90 \mathrm{mg} / \mathrm{kg}$ xylazine $13 \mathrm{mg} / \mathrm{kg}$ ) animals were thermally injured by 30 s exposure of the shaved lumbosacral skin to $70^{\circ} \mathrm{C}$ water, resulting in a second-degree burn that involved $\sim 28 \%$ of the total body surface area (8). Animals were kept under ketamine and xylazine anesthesia until sacrifice. At the time of killing, the abdominal cavity was opened, a 19-gauge needle was inserted into the inferior vena cava, and the blood was gently aspirated into a 5-ml plastic syringe containing $50 \mathrm{U}$ heparin. Rats were then killed by cervical dislocation. The blood was centrifuged $(1,000 \mathrm{~g})$ for $15 \mathrm{~min}$, resulting in separation of cells from plasma.

Osmotic fragility. RBC were tested for osmotic fragility by the modified procedure of Nelson (13). RBC were subjected to increasing hypotonicity in decreasing concentrations of $\mathrm{NaCl}$. The cells were allowed to stand at room temperature for $20 \mathrm{~min}$, then intact cells were removed by centrifugation. The absorbance values of supernatant fluids were determined at $540 \mathrm{~nm}$ and the percent hemolysis determined by reference to water-induced lysis of RBC. 
Measurement of red cell products. Several different approaches to identify and quantitate red cell products present in plasma of thermally injured rats were used (14). Plasma samples either diluted 1:10 in phosphate-buffered saline for direct absorbance studies, or undiluted samples were eluted from Sephacryl S-300 with phosphate-buffered saline. Samples were then measured for absorbance at $412 \mathrm{~nm}$ and also subjected to spectral scanning (350-650 nm) with a Beckman DU-6 UV/VIS spectrophotometer (Beckman Instruments, Fullerton, CA). Samples were also treated either with $15 \mathrm{mM}$ sodium dithionite or with $100 \mathrm{mM}$ sodium nitrite to determine if the respective reduction and oxidation products of hemoglobin occurred. Another quantitative measurement for the presence of hemoglobin included the benzidine converting activity that is associated with hemoglobin (15). When hemoglobin is present, the addition of $\mathrm{H}_{2} \mathrm{O}_{2}$ results in the conversion of benzidine to a condensation product that can be measured spectrophotometrically. The reference standard for this assay was crystalline rat hemoglobin obtained from Sigma Chemical Co. (St. Louis, MO). Rat hemoglobin was also measured immunochemically using precipitating antibody (Research Plus, Inc., Bayonne, $\mathrm{NJ}$ ) to rat hemoglobin in agarose gels employing double diffusion.

Column chromatography. Plasma samples obtained from rats $15 \mathrm{~min}$ after thermal injury were chromatographed on a Sephacryl S-300 column using phosphate-buffered (pH 7.4) saline at a flow rate of $\sim 0.5 \mathrm{ml} / \mathrm{cm}^{2}$ per $h$. Reference standards used in the chromatographic separation included dextran blue, equine cytochrome $c,{ }^{125}$ I-labeled bovine serum albumin, and phenol red. Fractions collected were tested for presence of hemoglobin using three methods. First, each fraction was measured spectrophotometrically at $412 \mathrm{~nm}$ and absorbance spectra $(350-650 \mathrm{~nm})$ were obtained to determine if the characteristic Soret spectra were present. Second, the fractions were tested in the benzidine conversion assay (see above). Finally, the samples were tested immunochemically for the presence of hemoglobin.

In vitro hemolysis studies. Heparinized whole rat blood $(1.0 \mathrm{ml})$ was incubated at $37^{\circ} \mathrm{C}$ for $15 \mathrm{~min}$ in a stationary water bath with the addition of $0.75 \mathrm{ml}$ physiologic saline containing $0.1 \mathrm{U}$ of the complement activator, CVF. Various manipulations were used to determine effects on in vitro hemolysis. Hemolysis was measured by the supernatant content of hemoglobin, using absorption at $412 \mathrm{~nm}$ as the endpoint. When PEGcatalase and PEG-SOD were used, $100 \mathrm{U} / \mathrm{ml}$ were added to the reaction vessel before addition of CVF. The iron chelator, deferoxamine mesylate $(0.25 \mathrm{mg} / \mathrm{ml})$ was purchased from Ciba-Geigy Corp. (Summit, NJ). Ironsaturated deferoxamine mesylate was prepared by adding $96 \mathrm{mg}$ of $\mathrm{FeCl}_{3} \cdot 6 \mathrm{H}_{2} \mathrm{O}$ to $1.0 \mathrm{ml}$ of a solution of deferoxamine mesylate $(250 \mathrm{mg} /$ $\mathrm{ml})$. Blood was obtained from neutrophil and complement-depleted animals and utilized to probe the in vitro requirements for these constituents on CVF-induced lysis. When used, phorbol myristate acetate (Sigma Chemical Co.) was added to the neutrophil suspension at a final concentration of $200 \mathrm{ng} / \mathrm{ml}$.

Measurement of complement components bound to rat erythrocytes. Blood samples were obtained by sampling of blood from tail veins of rats. Blood was withdrawn into heparin sulfate $(10 \mathrm{U} / \mathrm{ml}$ blood $)$ at various time points before and after thermal injury. Plasma and buffy coat cells were separated from red cells by centrifugation and the RBC washed twice in triethanolamine-buffered (pH 7.4) saline (TBS). RBC were adjusted to $40 \times 10^{6}$ cells $/ \mathrm{ml}$ and incubated $\left(15 \mathrm{~min}, 22^{\circ} \mathrm{C}\right)$ with a $1: 10$ dilution of either goat anti-rat C3 or goat anti-human C7 or C8 (Boehringer Mannheim Chemicals, Indianapolis, IN). Following incubation, the samples were centrifuged and the RBC washed twice with TBS and the cell pellet resuspended and incubated $\left(15 \mathrm{~min}, 22^{\circ} \mathrm{C}\right)$ with ${ }^{125} \mathrm{I}$-labeled swine anti-goat IgG (initial concentration of $0.7 \mathrm{mg} / \mathrm{ml}$ ) diluted $1: 1,000$ in TBS. The RBC suspensions were washed twice with TBS and radioactivity measured using a gamma counter (Gamma Trac 1191, TM Analytic Inc., Elk Grove Village, IL). Similar studies were performed using antibody (hemolysin)-sensitized sheep erythrocytes (SEA) incubated in a 1:100 dilution of fresh rat serum $\left(15 \mathrm{~min}, 32^{\circ} \mathrm{C}\right)$. Following incubation the washed and resuspended (to $4 \times 10^{7}$ cells $/ \mathrm{ml}$ ) red cells were then treated with anticomplement antibodies and evaluated as described above.

Red cell disappearance measurements. Radiolabeled sheep erythro- cytes $(\mathrm{RBC})$ were infused into rats in order to determine the $\mathrm{RBC}$ rates of clearance in the presence and absence of agents that protect against intravascular hemolysis following thermal injury and whether these protective interventions might affect the mononuclear cell phagocytic system. Accordingly, sheep RBC were suspended at a concentration of $2 \times 10^{9}$ cells $/ \mathrm{ml}$ in phosphate-buffered saline and incubated at $37^{\circ} \mathrm{C}$ for $45 \mathrm{~min}$ with $25 \mu \mathrm{Ci}$ sodium dichromate $\left({ }^{51} \mathrm{Cr}\right)$ with constant agitation. The cells were then washed twice and suspended in a final concentration of 2.7 $\times 10^{8} \mathrm{RBC} / \mathrm{ml}$. Normal rats were treated with intravenous infusions of $0.5 \mathrm{ml}$ of saline, PEG-catalase $(1,200 \mathrm{U} / \mathrm{kg})$, PEG-SOD $(1,025 \mathrm{U} / \mathrm{kg})$ or DMTU $(1,000 \mathrm{mg} / \mathrm{kg})$. Immediately thereafter rats received $1.0 \mathrm{ml}$ sheep RBC. At 15-min intervals of up to $105 \mathrm{~min}, 150-\mu \mathrm{l}$ blood samples were drawn from the inferior vena cava of animals that were anesthetized with sodium pentobarbital $\left(150 \mathrm{mg} / \mathrm{kg}\right.$, given intraperitoneally). ${ }^{51} \mathrm{Cr}$ radioactivity of the blood was measured in a gamma counter. Rates of disappearances of the radiolabel from blood were calculated by the use of $\log$ plots and regression analysis.

Statistical analysis. Data were plotted as the mean \pm standard error of the mean (SEM). The data were analyzed using Student's $t$ test.

\section{Results}

Time course of intravascular hemolysis following thermal injury. Rats subjected to thermal injury of skin consistently demonstrated evidence of intravascular hemolysis. At $0,7.5,15,30$, 60,120 , and 240 min following thermal injury of skin, plasma was examined (by absorbance at $\mathbf{4 1 2} \mathrm{nm}$ ) for hemoglobin content. As shown in Fig. 1 in which increases in plasma absorbance values are plotted, maximum increases in levels of absorbance were found in plasma $15 \mathrm{~min}$ following thermal trauma, with a multifold increase in values for plasma hemoglobin as compared with values of plasma obtained prior to thermal injury. In five separate experiments the increase in absorbance at $412 \mathrm{~nm}$ in the plasma of rats thermally injured 15 min earlier has been consistently found, varying on average from 6- to 12-fold ele-

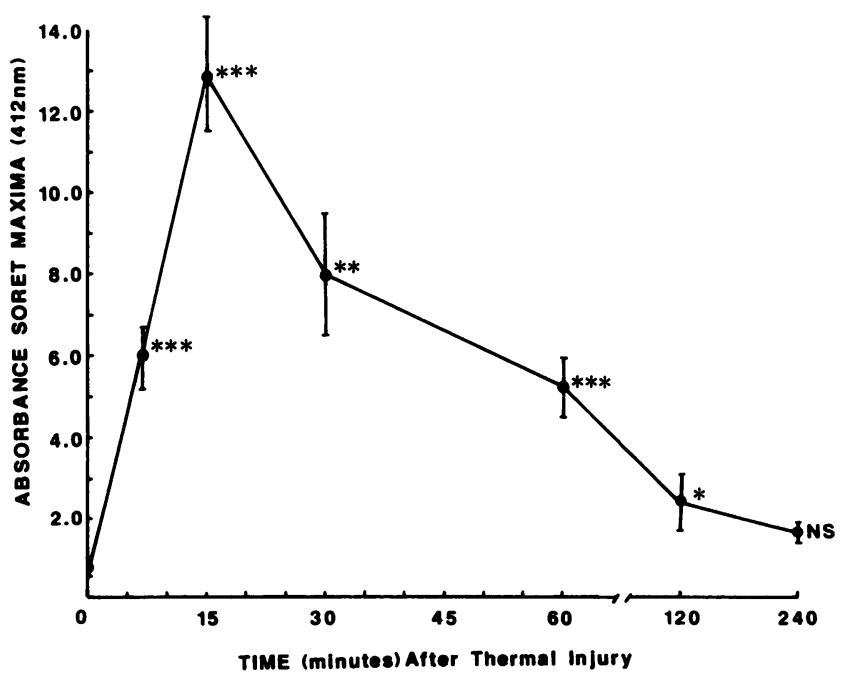

Figure 1. Time-course of hemoglobinemia following thermal injury of rat skin. For evaluation of hemolysis, spectral measurements of plasma hemoglobin were performed utilizing the Soret absorbance band (412 nm) and are expressed as fold increase in absorbance of plasma samples (diluted 1:10 in saline) when compared to plasma obtained prior to thermal injury. Each point represents the mean $( \pm$ SEM) of 10 individual animals. Time zero values are from plasma obtained prior to thermal injury. ${ }^{*} P<0.05,{ }^{* *} P<0.01,{ }^{* * *} P$ $<0.005$. 
vations in absorbance when compared to the values found in plasma obtained prior to thermal injury. That the absorbance pattern was consistent with the presence of hemoglobin was demonstrated by the characteristic spectral pattern (Soret bands) of absorbance with peaks at 578, 540, and 412-415 nm (Fig. 2).

In order to estimate the extent of intravascular hemolysis, known amounts of rat $\mathrm{RBC}$ were lysed in water and the resulting absorbance values (at $412 \mathrm{~nm}$ ) were used to construct a doseresponse curve. From this, it was then possible to obtain extrapolated values for the amount of hemolysis at six time points following thermal injury, using plasma obtained from each of four animals at all time points. The data shown in Table I indicate that the calculated amount of RBC destruction reached a peak at 15 min with slightly $<1 \%(0.88 \pm 0.047 \%)$ of the total $R B C$ mass being lysed. Although these are minimal estimates, the data suggest that the mass of RBC undergoing lysis is small.

An additional analysis of plasma was carried out using the measurement of benzidine-converting activity, which correlates with hemoglobin content (15). The results were compared to those employing absorbance values at $412 \mathrm{~nm}$. Plasma was obtained from five rats before and $15 \mathrm{~min}$ after acute thermal injury. As shown in Table II, there were, on average, 10-fold increases in absorbance values at $412 \mathrm{~nm}$ in plasma samples after thermal injury. With respect to the benzidine converting activity, these values rose on average by a factor of 9 (Table II). After constructing a dose-response curve for the benzidine converting activity present in crystalline rat hemoglobin, it was possible to calculate on the basis of data in Table II that $\sim 1.25 \%$ of the total red cell mass had undergone intravascular hemolysis, an estimate that closely approximated that based on hemoglobin content as assessed by $412 \mathrm{~nm}$ absorbance. These are minimal estimates since plasma turnover of hemoglobin has not been taken into consideration. At the time of sacrifice, the urine was

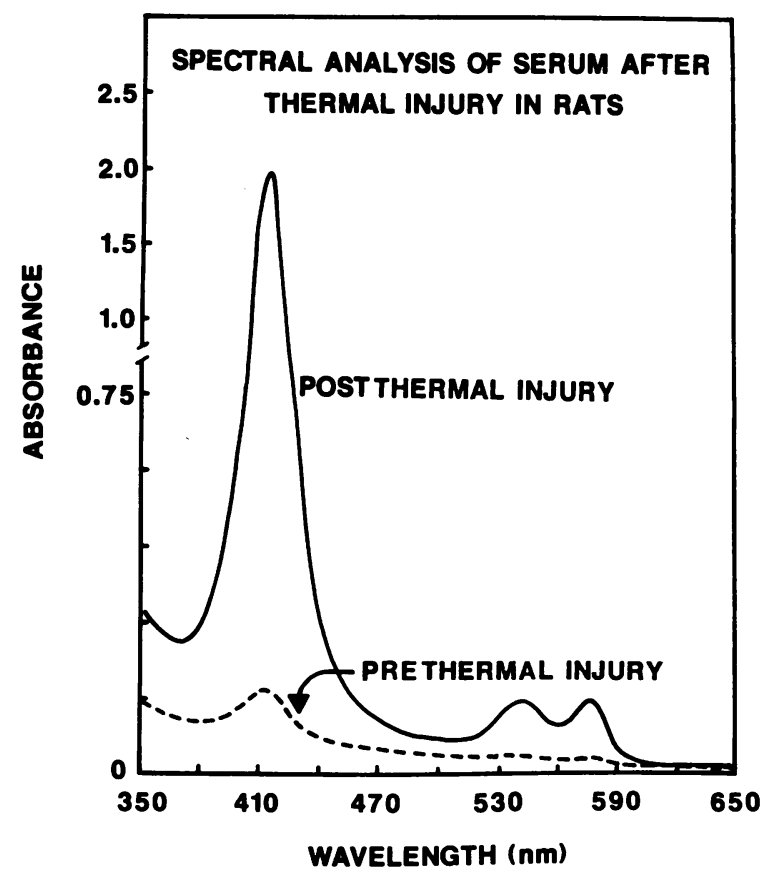

Figure 2. Typical spectral scans of plasma demonstrating the Soret bands indicative of hemoglobin (578, 540, and 412-415 nm). Scans were performed on plasma obtained from animals before and $15 \mathrm{~min}$ after thermal trauma to skin. Actual absorbance values are shown.
Table I. Extrapolated Values for Amount of Intravascular Hemolysis

\begin{tabular}{cll}
\hline $\begin{array}{l}\text { Time after } \\
\text { thermal injury }\end{array}$ & $\begin{array}{l}\text { Hemolysis of } \\
\text { total red cells* }\end{array}$ & Significance \\
\hline $\min$ & percent & P values \\
0 & $0.052 \pm 0.013$ & - \\
7 & $0.51 \pm 0.050$ & $<0.005$ \\
15 & $0.88 \pm 0.047$ & $<0.001$ \\
30 & $0.63 \pm 0.085$ & $<0.005$ \\
60 & $0.40 \pm 0.082$ & $<0.01$ \\
120 & $0.190 \pm 0.005$ & NS \\
240 & $0.100 \pm 0.005$ & NS \\
\hline
\end{tabular}

* See text for details.

pale yellow, suggesting that little hemoglobinuria had occurred at this early interval. We also noted that at the 15-min interval no fall in blood hematocrits had occurred (data not shown). These observations underscore the limited extent of acute intravascular hemolysis after thermal injury.

Nature of products in rat plasma. The question of the more precise identification of products present in the plasma of thermally injured rats was addressed. As indicated above, whole plasma diluted 1:10 showed the characteristic Soret spectrum of three peaks of absorbance (Fig. 2). The absence of absorbance at $624 \mathrm{~nm}$ excludes methemalbumin (16). When plasma was treated with sodium nitrite the absorbance peaks at 540 and 578 $\mathrm{nm}$ were lost, coincident with a new peak at $630 \mathrm{~nm}$, which correlates with the conversion of oxyhemoglobin to methemoglobin (16). Treatment of plasma from thermally injured rats with sodium dithionite caused loss of absorbance at 540 and $578 \mathrm{~nm}$ and resulted in the appearance of a new peak at 556 $\mathrm{nm}$, consistent with the reduction of oxyhemoglobin (16). When plasma from thermally injured rats was eluted from Sephacryl S-300 using phosphate-buffered saline, a small peak of absorbance (at $412 \mathrm{~nm}$ ) appeared in the void volume (as determined by the elution position of dextran blue) while a large absorbance peak was present in the position near the bovine serum albumin marker. On spectral scanning, this latter peak of material had the characteristic Soret-bands, behaved on treatment with sodium dithionite and sodium nitrite as would be expected of oxyhemoglobin (see above), and reacted immunochemically with antibody to rat hemoglobin with the production of a precipitin

Table II. Comparison of Red Cell Products in Plasma of Thermally Injured Rats *

\begin{tabular}{llllll}
\hline & \multicolumn{2}{l}{ Hemoglobin $(412 \mathrm{~nm})$} & & \multicolumn{2}{l}{ Benzidine conversion $(515 \mathrm{~nm})$} \\
\cline { 2 - 3 } $\begin{array}{lllll}\text { Animal } \\
\text { No. }\end{array}$ & Preburn & Postburn & & Preburn & Postburn \\
\hline 1 & 0.136 & 1.70 & & 0.280 & 3.00 \\
2 & 0.160 & 1.10 & & 0.358 & 2.39 \\
3 & 0.140 & 1.06 & & 0.139 & 2.32 \\
4 & 0.102 & 1.06 & & 0.310 & 2.20 \\
5 & 0.108 & 0.922 & & 0.201 & 1.51 \\
$\bar{x} \pm$ SEM & $0.129 \pm 0.011$ & $1.17 \pm 0.136$ & & $0.258 \pm 0.039$ & $2.28 \pm 0.237$
\end{tabular}

* Plasma was obtained before and 15 min after thermal injury. 
band in gel. Analysis (with absorbance at $412 \mathrm{~nm}$ ) of samples eluting from the Sephacryl column beyond the 60,000-D marker failed to reveal material in any fraction, suggesting that myoglobin and/or cytochrome do not contribute to any major extent to the absorbance values obtained with whole plasma. We also noted that when nonfractionated plasma samples pre- and postthermal injury were tested by Ouchterlony analysis with antibody against rat hemoglobin, precipitin bands were only found in the postthermal injury sera. In aggregate, these data suggest that hemoglobin is the main contributor to the material that is present in postthermal injury in rat plasma and absorbs at $412 \mathrm{~nm}$.

Analysis of $R B C$ for presence of complement components. To determine if $R B C$ from thermally injured rats show evidence of the presence of complement components on their cell surface, the studies described in Table III were carried out. As expected, opsonized and washed (SEA) that had been incubated with fresh rat serum when compared to nonopsonized sheep RBC (SE) that were similarly treated showed evidence of increased amounts of C3, C7, and C8 on their surfaces (Table III, experiment A). C3 was detected using antibody to rat $\mathrm{C} 3$, whereas $\mathrm{C7}$ and $\mathrm{C8}$ were detected by antibodies to human components. In experiment B, Table III, rat RBC obtained from each of five rats before and at 10 and $15 \mathrm{~min}$ after thermal injury failed to demonstrate evidence for increased uptake of complement components on RBC in the 15-min period after thermal injury when, as previously shown in Fig. 1, intravascular hemolysis reached its peak. The intravascular hemolysis occurring after thermal injury thus is not demonstrably accompanied by uptake of complement components by RBC. Obviously it is possible that very small amounts of complement proteins were not amenable to detection by these methods, or that uptake was very transient, or that RBC so modified were rapidly removed from the circulation.

Interventions protective against in vivo hemolysis. Previous investigations have described protective interventions (neutrophil depletion, iron chelators, oxygen radical scavengers) that will markedly reduce the lung injury occurring secondary to thermal injury of skin or following intravenous injection of CVF (8-10, 17). It has been previously established that these interventions do not interfere with activation of the complement system (10, 17). The effects of these interventions on the development of

Table III. Lack of Increased Amounts of Complement Components on $R B C$ from Thermally Injured Rats

\begin{tabular}{llll}
\hline & \multicolumn{4}{l}{ Complement component measured with antibody } \\
\cline { 2 - 4 } Experiment & C3 & C7 & C8 \\
\hline & $c p m$ & $c p m$ & $c p m$ \\
A. SEA + rat serum & 12,900 & 20,710 & 12,200 \\
SE + rat serum & 7,500 & 8,128 & 7,250 \\
B. Thermal injury & & & \\
O min & $14,529 \pm 201$ & $25,478 \pm 213$ & $19,482 \pm 287$ \\
10 min & $14,050 \pm 451$ & $25,420 \pm 1,035$ & $21,222 \pm 1,590$ \\
15 min & $14,699 \pm 244$ & $22,830 \pm 933$ & $20,629 \pm 45$
\end{tabular}

* In experiment A, all samples were examined in duplicate. Data represent averages of radioactivity readings. For details of procedure see Methods. For experiment B, at each interval erythrocytes were obtained from five thermally injured animals. intravascular hemolysis in thermally injured rats were determined. As shown in Fig. 3, hemoglobin levels, as determined by absorbance values (at $412 \mathrm{~nm}$ ) in plasma obtained from rats thermally injured 15 min earlier, increased nearly 16 -fold. In animals that were either previously depleted of complement or of neutrophils, there were substantial reductions (83.2 and $92.5 \%$, respectively) in the amounts of hemolysis. Treatment of rats with either PEG-SOD or PEG-catalase, or the combination of both enzymes, led to a reduction in the amount of intravascular hemolysis by $85-89 \%$. Treatment of rats with either of two $\mathrm{HO}^{\circ}$ scavengers, DMSO or DMTU, also reduced the amount of hemoglobinemia by $63-86 \%$. Although these data do not define the precise nature of the oxygen radicals involved in the hemolytic process following thermal injury, they suggest that oxygen radicals from complement-activated neutrophils are responsible for the intravascular hemolysis observed.

Osmotic fragility of rat $R B C$. RBC isolated from rats $15 \mathrm{~min}$ after thermal injury were subjected to a range of hypotonic concentrations of $\mathrm{NaCl}$ and the amount of lysis determined spectrophotometrically, as shown in Fig. 4. Using the values obtained with $0.45 \%$ (wt/vol) $\mathrm{NaCl}, \mathrm{RBC}$ from thermally injured rats showed $55.9 \%$ hemolysis compared with $2.76 \%$ hemolysis of RBC obtained from nonthermally injured (control) rats. The protective effect in thermally injured rats of catalase is clearly shown in Fig. 4 in which no increased osmotic fragility of RBC was found. The effects on RBC osmotic fragility of in vivo protective interventions that reduce the amount of intravascular hemolysis are shown in Table IV in which RBC were obtained from thermally injured or nonthermally injured rats, with and without protective interventions. The concentrations of $\mathrm{NaCl}$ that caused 50\% lysis of the RBC obtained from these animals are shown. Each of the in vivo protective interventions (neutrophil depletion, complement depletion, PEG-catalase) employed

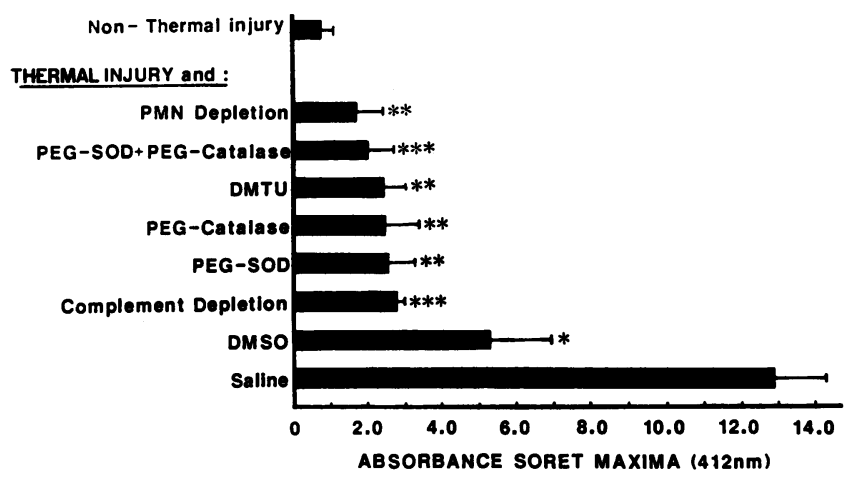

Figure 3. Effect of protective interventions on intravascular hemolysis in thermally injured rats at 15 min after skin burns. Data are expressed in a manner similar to that in Fig. 1. Animals were pretreated $10 \mathrm{~min}$ prior to thermal injury with PEG-catalase $(1,200 \mathrm{U} / \mathrm{kg}$ or PEG-SOD $(1,025 \mathrm{U} / \mathrm{kg})$ (both intravenously administered) or with DMTU $(1,000 \mathrm{mg} / \mathrm{kg})$ or DMSO $(1.5 \mathrm{ml} / \mathrm{kg})$ injected intraperitoneally. Complement and neutrophil (PMN) depletion were accomplished by intraperitoneal injection of CVF ( $40 \mathrm{U} / \mathrm{rat})$ and rabbit antiserum $(5.0 \mathrm{ml} / \mathrm{kg}$ body $\mathrm{wt})$ against rat neutrophils at 24 and $18 \mathrm{~h}$, respectively, prior to thermal injury. The Soret band $(412 \mathrm{~nm})$ was utilized for the quantitative determination of hemolysis. Each bar represents the mean $( \pm \mathrm{SEM})$ of intravascular hemolysis from five separate animals. Significance ( $P$ value) of each point was derived by comparison with plasma hemoglobin values of unprotected thermally injured rats $\left({ }^{*} P<0.05,{ }^{* *} P<0.005,{ }^{* * *} P<0.001\right)$. 


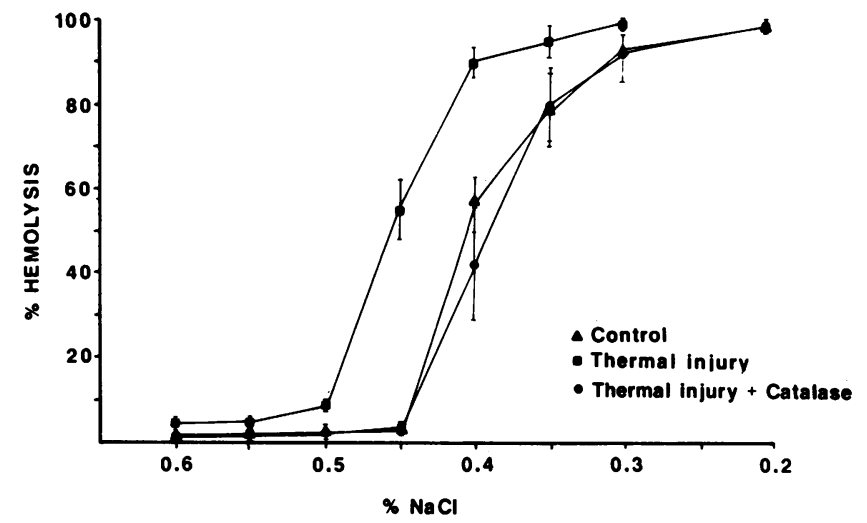

Figure 4. Effects of protective interventions on osmotic fragility of $\mathrm{RBC}$ obtained from thermally injured rats. $\mathrm{RBC}$ were first washed with saline and incubated with various concentrations of $\mathrm{NaCl}$. Each curve represents the mean ( \pm SEM) of hemolysis using RBC from four different animals. The comparisons were with "control" RBC, which were obtained from rats that were not thermally injured. Treatment of thermally injured animals with catalase prevented the development of increased osmotic fragility in RBC.

in thermally injured rats, as outlined in Table IV, caused reversal of osmotic fragility values to the values obtained from nonthermally injured rats. In other words, saline concentrations causing $50 \%$ lysis of erythrocytes obtained from thermally injured rats that had been subjected to protective interventions were not significantly different from saline concentrations that lysed (50\%) red cells obtained from rats without skin burns. Treatment of thermally injured rats with PEG-catalase that had been previously heat inactivated $\left(56^{\circ} \mathrm{C}, 60 \mathrm{~min}\right)$ did not alter the increased osmotic fragility of RBC, suggesting that neither PEG alone nor inactive catalase alone can explain the results observed in Table IV. It can also be seen (Table IV) that neutrophil or complement depletion or catalase treatment of nonthermally injured rats did not per se affect the osmotic fragility values of erythrocytes. These data indicate that interventions that diminish the amount of intravascular hemolysis following thermal injury also prevent the appearance of osmotically fragile RBC.

Effects of protective interventions in clearance of sheep $R B C$. In order to determine if interventions that protect against intravascular hemolysis might be altering functions of the mono- nuclear phagocytic cell system, rats in groups of two each were treated with saline, PEG-catalase, PEG-SOD, or DMTU in the same dosage schedules as described above. In the first set of experiments the $t_{1 / 2}$ values for sheep RBC survival in saline, PEG-catalase or PEG-SOD treated (but not thermally injured) rats were 19,16 , and $18 \mathrm{~min}$, respectively. In a second group of animals the relevant values in saline or DMTU-treated rats were 13 and $10 \mathrm{~min}$, respectively. These data indicate that the protective antioxidant interventions do not have substantial effects on clearance of heterologous RBC, suggesting that the mononuclear phagocytic cell system is not altered by these interventions.

Development of an in vitro model of hemolysis. In order to determine if an in vitro model could simulate the in vivo observations, CVF was added in limited amounts to rat blood $(0.1$ $\mathrm{U} \mathrm{CVF} / \mathrm{ml}$ blood) and the amount of hemolysis measured. Details of these procedures are described above. As shown in Table $\mathrm{V}$, there was a 23-fold increase in the absorbance (at $412 \mathrm{~nm}$ ) of plasma after addition of CVF to whole blood, which was incubated at $37^{\circ} \mathrm{C}$ for $15 \mathrm{~min}$ in a static water bath. A reduction (by $68 \%$ ) in hemolysis occurred when catalase $(100 \mathrm{U} / \mathrm{ml}$ blood) was present. A similar reduction in hemolysis was obtained with the presence of an equivalent amount of superoxide dismutase (SOD). The hemolytic event was also susceptible to the presence of the iron chelator deferoxamine $(0.25 \mathrm{mg} / \mathrm{ml})$ in which case there was a $73 \%$ reduction in the amount of hemolysis. The specificity of this protective activity was demonstrated by the loss of protective effects (only $15.2 \%$ ) when iron-saturated deferoxamine was used. These interventions did not interfere with CVF-induced in vitro activation of complement, as determined by CH50 values (data not shown). Also, addition in vitro of CVF to blood from complement-depleted rats showed a $45.1 \%$ reduction in the amount of hemolysis, as was also the case (51.3\% reduction) when blood was obtained from rats that had been neutrophil depleted. Reasons for the incomplete inhibition of hemolysis caused by addition of CVF to blood obtained from either complement depleted or neutrophil-depleted rats is probably related to incomplete depletion of the blood elements. For comparison, it was demonstrated that addition of $200 \mathrm{ng}$ of the potent leukocyte activator phorbol myristate acetate (PMA) to normal rat blood $(1.0 \mathrm{ml})$ resulted in hemolysis that was at least as effective as that produced by addition of CVF to rat blood (Table V). PMA treatment of rat blood had no effect on serum

Table IV. Osmotic Fragility Values for RBC from Treated Rats

\begin{tabular}{lllll}
\hline Thermal injury & No. of animals & Intervention & Value for osmotic fragility* & Significancef \\
\hline & & & $\bar{x} \pm S E M$ & \\
No & 11 & None & $0.405 \pm 0.002$ & - \\
Yes & 4 & None & $0.460 \pm 0.005$ & $<0.001$ \\
Yes & 4 & Neutrophil depletion & $0.400 \pm 0.007$ & NS \\
Yes & 4 & Complement depletion & $0.389 \pm 0.010$ & NS \\
Yes & 3 & PEG-catalase $(1,200 \mathrm{U} / \mathrm{kg})$ & $0.403 \pm 0.010$ & NS \\
Yes & 3 & PEG-catalase $(1,200 \mathrm{U} / \mathrm{kg})$, heat-inactivated & $0.456 \pm 0.006$ & $<0.001$ \\
No & 2 & Neutrophil depletion & $0.400 \pm 0.007$ & NS \\
No & 2 & Complement depletion & $0.392 \pm 0.001$ & NS \\
No & 2 & PEG-catalase $(1,200 \mathrm{U} / \mathrm{kg})$ & $0.405 \pm 0.004$ & NS
\end{tabular}

* Concentration (percent, weight per volume) of $\mathrm{NaCl}$ causing lysis of $50 \%$ of $\mathrm{RBC}$. $¥$ Compared to $\mathrm{RBC}$ from nonthermally injured rats; $\mathrm{NS}$, not significant. 
complement activity (data not shown). These results suggest that, under the conditions employed, activation of complement in whole blood will lead to a hemolytic event that requires the role of complement and neutrophils and is dependent on the generation of oxygen radicals in the presence of iron. This in vitro model supports the findings obtained in the thermally injured rats in which the intravascular hemolysis appears to be the result of iron-dependent toxic oxygen products generated by complement-activated neutrophils $(8,9)$.

\section{Discussion}

We have demonstrated that thermal trauma of rat skin leads to limited but consistent intravascular hemolysis. It has been shown by others that oxygen radical species derived from leukocytes may participate directly in destruction of red cells both in vitro or in vivo $(3-5,18-21)$. It is well established that thermal injury activates the complement system, although the precise mechanism by which this occurs is currently unknown (8). Complement activators are also known to produce changes in RBC directly via lysis associated with the C5b-9 membrane attack complex or indirectly via opsonization of $\mathrm{RBC}$ following uptake of $\mathrm{C} 3 \mathrm{~b}$ $(1,2,22,23)$. In the current studies, depletion of either complement or circulating neutrophils precluded pathophysiologic events necessary for the induction of intravascular hemolysis after thermal injury. The depletion of circulating neutrophils prior to thermal trauma protected against the rise in plasma levels of hemoglobin as compared to changes in thermally injured animals not previously depleted of neutrophils. On the other hand, the absolute requirement for both complement as well as neutrophils and the protective effects of SOD, catalase, and $\mathrm{HO}^{\circ}$ scavengers imply that the generation of toxic oxygen products from neutrophils is the closest link to $\mathrm{RBC}$ destruction and that complement activation products probably participate in this sequence by stimulation of neutrophils. This assumption is further supported by the fact that red cells from thermally injured rats did not reveal evidence of complement uptake (Table III), that the burn-related hemolysis could be simulated in vitro by complement or phorbol ester-activated blood neutrophils (Table V), and that in vivo as well as in vitro the presence of hydroxyl radical scavengers (DMSO, DMTU) or other protective agents (catalase, superoxide dismutase, deferoxamine), which neither affect the complement activity $(10,17)$ nor interfere with enzyme secretion or generation by stimulated neutrophils of $\mathrm{O} \dot{\overline{2}}$ or $\mathrm{H}_{2} \mathrm{O}_{2}$ (24), significantly diminished the development of hemolysis. What seems likely is that the intravascular hemolysis in thermally injured rats is not the direct result of interaction of RBC with complement activation products such as the membrane attack complex.

Although we were unable to detect uptake of complement components onto RBC obtained from thermally injured rats (Table III), these negative data need to be viewed with caution. It is possible that the techniques are not sufficiently sensitive to detect small amounts of complement taken up on the surfaces of $\mathrm{RBC}$. It is also possible that RBC coated with products such as $\mathrm{C} 3 \mathrm{~b}$ are rapidly sequestered into sites such as the spleen or the liver, where interaction with phagocytic cells results in their lysis. Also to be emphasized, our calculations (described above) suggest that the number of $\mathrm{RBC}$ undergoing lysis is quite small (estimated to be $\sim 1 \%$ ), which implies a formidable challenge to identify such a small population of cells, especially if their uptake of complement components is very limited. The question is still open as to whether complement-induced modification of RBC is important in the neutrophil-dependent and oxygen radical-mediated process of lysis of RBC.

Whether adherence-promoting factors play a role in the in vivo intravascular hemolytic process in our model of acute thermal injury is unknown. The interaction of $\mathrm{C} 3 \mathrm{~b}$-coated $\mathrm{RBC}$ could lead to enhanced adherence between RBC and neutrophils (25). Oxidatively altered RBC might be reactive with "antisenescent" immunoglobulin (26), resulting in enhanced interaction with neutrophils via $\gamma$-Fc receptors on neutrophils. In preliminary studies we have examined RBC obtained from the blood $5,10,15 \mathrm{~min}$ after thermal injury and have not been able to detect by indirect agglutination techniques the presence of $\mathrm{IgG}$ or IgM on RBC surfaces (Hatherill et al., unpublished data), but agglutination techniques are relatively insensitive, suggesting that these negative data must be viewed with caution.

In the case of endothelial cell or RBC lysis induced by neutrophils stimulated with phorbol ester, C5a, or immune complexes (Table V) $(3,5,24,27,28)$ there is no doubt that the lytic process can occur without the exogenous addition of adherencepromoting proteins. Some investigators facilitate neutrophiltarget cell interaction by centrifugal means (27), although in most other studies this is not done. On the other hand, there

Table V. In Vitro Hemolysis Induced in CVF-Treated Rat Blood

\begin{tabular}{|c|c|c|c|c|c|}
\hline Blood donor & Treatment of blood & $\begin{array}{l}\text { No. of } \\
\text { animals }\end{array}$ & Hemolysis & Significance & $\begin{array}{l}\text { Protection from } \\
\text { hemolysis }\end{array}$ \\
\hline . & & & $412 \mathrm{~nm}$ & & \\
\hline Normal & None & 4 & $0.79 \pm 0.19$ & - & - \\
\hline Normal & $\mathrm{CVF}^{*}$ & 6 & $17.93 \pm 0.29$ & $<0.001$ & - \\
\hline Normal & CVF + catalase $(100 \mathrm{U} / \mathrm{ml})$ & 6 & $6.27 \pm 0.71$ & $<0.001$ & 68.0 \\
\hline Normal & $\mathrm{CVF}+\mathrm{SOD}(100 \mathrm{U} / \mathrm{ml})$ & 7 & $5.73 \pm 0.25$ & $<0.001$ & 71.2 \\
\hline Normal & CVF + deferoxamine $(0.25 \mathrm{mg} / \mathrm{ml})$ & 6 & $5.35 \pm 0.53$ & $<0.001$ & 73.4 \\
\hline Normal & CVF + iron saturated deferoxamine $(0.25 \mathrm{mg} / \mathrm{ml})$ & 6 & $15.27 \pm 0.78$ & $<0.001$ & 15.2 \\
\hline Complement-depleted & CVF & 4 & $10.20 \pm 1.79$ & $<0.005$ & 45.1 \\
\hline PMN-depleted & CVF & 6 & $9.13 \pm 1.21$ & $<0.001$ & 51.3 \\
\hline Normal & PMA (200 ng/ml) & 4 & $20.8 \pm 1.7$ & $<0.001$ & - \\
\hline
\end{tabular}

$* 0.1 \mathrm{U} / 1.0 \mathrm{ml}$ rat blood. 
can be no question that any process that will facilitate physical contact between neutrophils and target cells will likely enhance the extent of cell lysis. Indeed, our inability to detect complement products such as $\mathrm{C} 3 \mathrm{~b}$ on the $\mathrm{RBC}$ surfaces from thermally injured rats may explain why the extent of hemolysis is quite limited, being the result of random encounters between RBC and activated neutrophils within the vascular compartment.

Human RBC exposed in vitro to toxic oxygen species from neutrophils incubated with zymosan-activated serum (4) or with phorbol myristate acetate (5) showed evidence of erythrocyte membrane peroxidation and lytic reactions. It has been suggested that lysis, in part, is due to the influx of $\mathrm{O}_{2}^{-}$through the anionic channel and that intracellularly methemoglobin is produced in parallel with chemical events leading to lysis (27). It has been demonstrated that $\mathrm{RBC}$ exposed in vitro to relatively high concentrations of $\mathrm{H}_{2} \mathrm{O}_{2}$ develop evidence of lipid peroxidation, as indicated by the appearance of malondialdehyde (29). There is also evidence that, under conditions of exposure of $\mathrm{RBC}$ to oxidants, cross-linking of membrane glycoproteins and sulfhydrylcontaining compounds occurs, resulting in an osmotically fragile RBC membrane (30). Whether any similar biochemical changes are occurring in the RBC of animals thermally injured remains to be determined. However, morphometric analysis of RBC obtained from thermally injured animals have to date consistently failed to detect altered shape or RBC size as compared with RBC controls. Red cells obtained from rat blood before and 10 and $15 \mathrm{~min}$ after acute thermal injury have been examined for mean corpuscular volume using a Coulter counter with a channelyzer (Coulter Instruments, Hialeah, FL). In each of three animals at these three time points the curves determined by channel positions indicative of red cell volume were superimposable (Bruner et al., unpublished observation). These data suggest that in the events that occur immediately after thermal injury and culminate in intravascular hemolysis there is no measurable evidence of red cell volume change corresponding with or predictive of the hemolytic event. If the total red cell mass undergoing lysis is small ( $<1.5 \%$ as suggested above), and if only these RBC destined to undergo lysis show volume changes, this may well be below the limits of detection.

It is noteworthy that hemolysis measured by ${ }^{51} \mathrm{Cr}$-release from erythrocytes or endothelial cells incubated in the presence of neutrophils and PMA displayed maximal release in the supernatant between 1.5 and $4 \mathrm{~h}(5,28)$. In the current study, hemolysis as measured by plasma hemoglobin content obtained in whole blood of thermally injured rats reached a peak within $15 \mathrm{~min}$. In contrast, in vitro lysis of RBC or endothelial cells by phorbol-stimulated neutrophils is a slow process requiring several hours for completion $(5,24)$. On the other hand, infusion of CVF into rats results in acute injury and necrosis of endothelial cells within the lung microvasculature, with a peak of injury occurring in $30 \mathrm{~min}(10)$, a process far more rapid than that found in vitro (24). These diverse observations are difficult to compare because of the different end points and the dissimilarities of whole animal studies compared with in vitro systems. Factors that account for the substantial differences in terms of time required for hemolysis or endothelial cell damage in vitro and in vivo cannot be definitively explained at present. It is possible that thermal trauma in some manner alters $R B C$ to make them more susceptible to toxic oxygen products from complement-activated neutrophils. Either the thermal trauma per se could make the RBC more sensitive or RBC could be altered by contact with other factors (such as products of lipid peroxidation) that appear very early in the plasma following thermal injury of the skin (9).

The data reported in this paper suggest that acute hemoglobinemia occurring after thermal injury is the result of toxic oxygen products generated from activated neutrophils following activation of the complement system. Since hemoglobinemia in humans is frequently associated with the development of acute renal tubular necrosis and acute renal failure, and since our data suggest the availability of interventions to prevent $\mathrm{RBC}$ damage, further investigations into the role of toxic oxygen products from leukocytes in the causation of intravascular hemolysis are warranted.

The recent studies of Snyder et al. (31) shed some light on the ability of $\mathrm{H}_{2} \mathrm{O}_{2}$ to react with human $\mathrm{RBC}$ in a manner that causes cross linking of spectrin to hemoglobin. RBC modified in this manner undergo echinocyte formation and reveal diminished susceptibility of phosphatidylcholine to hydrolysis by bee venom phospholipase, suggesting that changes in the inner bilayer of the cell membrane of the RBC together with cross linking of spectrin and hemoglobin may be linked to the changes. It has also been shown that $\mathrm{RBC}$ modified by exposure to $\mathrm{H}_{2} \mathrm{O}_{2}$ become adherent to and phagocytized by blood monocytes. Oxidatively altered RBC may be reactive with IgG antibody to $\alpha$ galactosyl residues (26). Whether RBC modified in this manner stimulate phagocytic cells to produce an oxygen radical burst that will cause $\mathrm{RBC}$ lysis, is a question we are currently exploring.

\section{Acknowledgment}

This work was supported in part by National Institutes of Health grants GM-28499, GM-29507, HL-28442, and HL-31963.

\section{References}

1. Müller-Eberhard, H. J. 1975. Complement. Annu. Rev. Biochem. 44:697-724.

2. Esser, A. F. 1982. Interactions between complement proteins and biological and model membranes. In Biological Membranes. D. Chapman, editor. Academic Press, New York. 4:277-325.

3. Sacks, T., C. F. Moldow, P. R. Craddock, T. K. Bowers, and H. S. Jacob. 1978. Oxygen radicals mediate endothelial cell damage by complement-stimulated granulocytes: An in vitro model of immune vascular damage. J. Clin. Invest. 61:1161-1167.

4. Claster, S., D. T. Y. Chio, A. Quintanilha, and B. Lubin. 1984. Neutrophils mediate lipid peroxidation in human red cells. Blood. 64: 1079-1084.

5. Weiss, S. J. 1980. The role of superoxide in the destruction of erythrocyte targets by human neutrophils. J. Biol. Chem. 225:99129917.

6. Loebl, E. C., C. R. Baxter, and E. A. Curreri. 1973. The mechanism of erythrocyte destruction in the early post-burn period. Ann. Surg. 178: 681-686.

7. Loebl, E. C., J. A. Marvin, P. W. Curreri, and C. R. Baxter. 1974. Erythrocyte survival following thermal injury. J. Surg. Res. 16:96-101.

8. Till, G. O., C. Beauchamp, D. Menapace, W. Tourtellotte, R. Kunkel, K. J. Johnson, and P. A. Ward. 1983. Oxygen radical-dependent lung damage following thermal injury of rat skin. J. Trauma. 23:269277.

9. Till, G. O., J. R. Hatherill, W. W. Tourtellotte, M. J. Lutz, and P. A. Ward. 1985. Lipid peroxidation and acute lung injury after thermal trauma to skin: Evidence of a role for hydroxyl radical. Am. J. Pathol. 119:376-384.

10. Till, G. O., K. J. Johnson, R. Kunkel, and P. A. Ward. 1982. Intravascular activation of complement and acute lung injury. Depen- 
dency on neutrophils and toxic oxygen metabolites. J. Clin. Invest. 69: 1126-1135.

11. Johnson, K. J., and P. A. Ward. 1974. Acute immunologic pulmonary alveolitis. J. Clin. Invest. 54:349-357.

12. Ballow, M., and C. G. Cochrane. 1969. Two anticomplementary factors in cobra venom. Hemolysis of guinea pig erythrocytes by one of them. J. Immunol. 103:944-952.

13. Nelson, A. D. 1979. Erythrocyte disorders. In Clinical Diagnosis and Management by Laboratory Methods. J. B. Henry, editor. W.B. Saunders Co., Philadelphia, 964-1035.

14. Lemberg, R., and J. W. Legge. 1949. Hematin compounds and bile pigments: their constitution, metabolism and function. Wiley Interscience, New York, p. 228.

15. Crosby, W., and F. Furth. 1956. A modification of the benzidine method for measurement of hemoglobin in plasma and urine. Blood. 11:380-383.

16. Miale, J. B. 1982. Laboratory Medicine Hematology. C.V. Mosby Co., St. Louis. 876-877.

17. Ward, P. A., G. O. Till, R. Kunkel, and C. Beauchamp. 1983. Evidence for role of hydroxyl radical in complement and neutrophildependent tissue injury. J. Clin. Invest. 72:789-801.

18. Babior, B. M. 1981. Oxidizing radicals and red cell destruction. In The Function of Red Blood Cells: Erythrocyte Pathobiology. E. F. H. Wallach, editor. Alan R. Liss, Inc., New York. 173-195.

19. Jacob, H. S., and S. E. Lux. 1968. Degradation of membrane phospholipids and thiols in peroxide hemolysis: Studies in vitamin E deficiency. Blood. 32:549-568.

20. Clark, A., and N. H. Hunt. 1983. Evidence for reactive oxygen intermediates causing hemolysis and parasite death in malaria. Infect. Immun. 39:1-6.

21. Tomoda, A., H. Suzuki, Y. Kukuhara, A. Ueda, K. Niho, Y. Yoneyama, and K. Kanima. 1981. Involvement of active oxygens released by activated leukocytes in hemolytic mechanism of G6PD-deficient red cells. Acta Haematol. Jpn. 47:189-194.

22. Pickering, R. J., M. R. Wolfson, R. A. Good, and H. Gewurz.
1969. Passive hemolysis by serum and cobra venom factor. A new mechanism inducing membrane damage by complement. Proc. Natl. Acad. Sci., USA. 62:521-527.

23. Miyama, A., T. Kato, I. Minoda, T. Ueda, and S. Kashiba. 1976. Activation of terminal components of human complement by a trypsinactivated complex of human factor B and cobra venom factor. Jpn. J. Microbiol. 20:507-516.

24. Varani, J., S. E. G. Fligiel, G. O. Till, R. G. Kunkel, U. S. Ryan, and P. A. Ward. 1985. Pulmonary endothelial cell killing by human neutrophils: possible involvement of hydroxyl radical. Lab. Invest. 53: 656-663.

25. Jack, R. M., and P. A. Ward. 1980. Babesia rodhaini interactions with complement: relationship to parasitic entry into red cells. J. Immunol. 124:1566-1573.

26. Galili, U., E. A. Rachmilewitz, A. Peleg, and I. Flechner. 1984. A unique natural human IgG antibody with anti- $\alpha$-galactosyl specificity. J. Exp. Med. 160:1519-1531.

27. Weiss, S. J. 1982. Neutrophil-mediated methemoglobin formation in the erythrocyte. J. Biol. Chem. 257:2947-2953.

28. Van Asbeck, B. S., J. Hoidal, G. M. Vercellotti, B. A. Schwartz, C. F. Moldow, and H. S. Jacob. 1985. Protection against lethal hyperoxia by tracheal insufflation of erythrocytes: role of red cell glutathione. Science (Wash. DC). 227:756-759.

29. Stocks, J., and T. L. Dormandy. 1971. The autoxidation of human red cell lipids induced by hydrogen peroxide. Br. J. Haematol. 20:95111.

30. Haest, C. W. M., D. Kamp, G. Plasa, and B. Deuticke. 1977. Intra- and intermolecular cross-linking of membrane proteins in intact erythrocytes and ghosts by SH-oxidizing agents. Biochem. Biophys. Acta. 469:226-230.

31. Snyder, L. M., N. L. Fortier, J. Tainor, J. Jacobs, L. Leb, B. Lubin, D. Chin, S. Shohet, and N. Mohandas. 1985. Effect of hydrogen peroxide exposure on normal human red cell deformability, morphology, surface characteristics, and spectrin-hemoglobin cross-linking. J. Clin. Invest. 76:1971-1977. 